\title{
Plasma Enhanced-Chemical Vapour Deposition of Scuff-Resistant Hydrogenated Amorphous Carbon Coatings on C100 Steel
}

\author{
Nicoletta De Vietro ${ }^{1}$, Gianluigi Intonti ${ }^{1}$, Francesco Fracassi ${ }^{1}$, Gianluca Quarta ${ }^{2}$, \\ Lucio Maruccio², Lucio Calcagnile ${ }^{2}$ \\ ${ }^{1}$ Department of Chemistry, University of Bari “Aldo Moro”, Bari, Italy \\ ${ }^{2}$ CEDAD (Centre for Dating and Diagnostics), Department of Engineering for Innovation, University of Salento, \\ Lecce, Italy \\ Email: ${ }^{*}$ nicoletta.devietro@uniba.it
}

Received 3 February 2014; revised 2 March 2014; accepted 1 April 2014

Copyright (C) 2014 by authors and Scientific Research Publishing Inc.

This work is licensed under the Creative Commons Attribution International License (CC BY). http://creativecommons.org/licenses/by/4.0/

(c) (i) Open Access

\begin{abstract}
Hydrogenated amorphous carbon coatings, deposited by low pressure plasma to minimize the wear of C100 steel components, were optimized and characterized. In order to ensure good adhesion of the films to the steel surface, a thin Ti interlayer was deposited, by magnetron sputtering, before the plasma deposition. The chemical characterization of the deposits was performed by means of RAMAN, XPS, RBS and ERDA analysis, while nanoindentation, nanoscratch and nanowear tests allowed to estimating the tribomechanical properties of the deposits, with the aim of evaluating their scuff-resistance. It was found that the optimized plasma deposited hydrogenated amorphous carbon coatings were well adherent to $\mathrm{C100}$ steel and increased more than $70 \%$ its surface hardness.
\end{abstract}

Keywords

PE-CVD, C100 Steel, Scuff-Resistant a-C:H Coatings

\section{Introduction}

The efficiency of a diesel engine, in terms of maintenance of performance over time (e.g. its power, fuel consumption and emissions) is related not only to purely engineering design, but also to the choice of appropriate

${ }^{*}$ Corresponding author.

How to cite this paper: De Vietro, N., et al. (2014) Plasma Enhanced-Chemical Vapour Deposition of Scuff-Resistant Hydrogenated Amorphous Carbon Coatings on C100 Steel. Journal of Surface Engineered Materials and Advanced Technology, 4, 131-139. http://dx.doi.org/10.4236/jsemat.2014.43017 
component materials. Selection of scuff-resistant materials or appropriate surface treatments and coatings, for example, can significantly contribute to minimize problems correlated to the operation of fuel injectors and pumps, which are generally due to the high injection pressures, high temperatures, low lubricity and fuel contamination (e.g. water or abrasives). DLC films, thanks to their excellent hardness and wear resistance, are widely studied as protective coatings of components of fuel injectors and fuel pumps [1] [2].

The $\mathrm{sp}^{2}$ to $\mathrm{sp}^{3}$ carbon ratio and the hydrogen content define the type of DLC coating and, consequently, its properties [2]. A typical DLC coating, obtained by plasma enhanced-chemical vapor deposition (PE-CVD) technique, contains $40 \%-60 \%$ of $\mathrm{sp}^{3}$ carbon, 30 - 50 atomic \% of hydrogen and is classified as hydrogenated amorphous carbon (a-C:H) [3]. This kind of coating is particularly suitable for applications that require a medium strength and good surface uniformity.

Due to bond distortion, a-C:H is characterized by high intrinsic stress [4] and low adhesion to many types of substrates (e.g. polymers, metallic alloys), with limitation of its utilization for severe tribological applications, included those involving sliding contacts not or only marginally lubricated. Different approaches have been proposed to overcome the poor adhesion of hard DLC, e.g. the deposition of a metal or of a nanostructured Me-C interlayer, where Me is a metal with high affinity to carbon (e.g. Ti, W or Cr), or the deposition of nanostructured Me-C coating [5]-[8].

In this paper, for the first time, C100, a steel used in specific fields such as the building of bearings, diesel engine components and deep frozen walls [9], was covered with plasma deposited a-C:H coatings. Thin interlayers of Ti were tested to improve the adhesion of DLC on the selected substrate, according to the studies about which this metal improves the adhesion of DLC films on other kinds of steel [10]-[12]. In this way, it should be possible to solve one of the most severe limitation of the use of the C100 steel for the production of diesel engine components, the fact that low lubricity fuels can cause wear (both abrasion and adhesion wear) of steel fuel injector component, with fuel injector tip failure and consequent overall performance degradation of the fuel injector [13]. An adherent hard carbon coating ensures high abrasion resistance of tribologically stressed components for commercial use in diesel engine or other heavy duty engine applications.

It was shown that the best adhesion strength can be increased at about $1690 \mu \mathrm{N}$ and that the plasma deposited a-C:H coatings improved more than $70 \%$ the surface hardness of covered C100 steel samples.

A tribomechanical and chemical characterization of selected coating is also reported.

\section{Materials and Methods}

The experimental apparatus utilized for the deposition of a-C:H coatings (Figure 1) consists of a cylindrical low pressure plasma reactor with an asymmetric electrode configuration (70 mm inter-electrode distance), pumped by a turbomolecular-rotary pumping system. The pressure is measured and controlled in the $0-133.32$ Pa range with a baratron gauge and an automatic throttle valve. The lower stainless steel circular electrode (diameter, 190 $\mathrm{mm}$ ), on which the substrates were positioned during the deposition, was thermally controlled, at $50^{\circ} \mathrm{C}$, by means of a circulating water and glycol mixture, while the upper electrode is a circular balanced magnetron sputtering (MS) source (diameter, $76.2 \mathrm{~mm}$ ) equipped with a grounded shutter. Both electrodes are powered with $13.56 \mathrm{MHz}$ radio frequency (RF) power supplies with automatic matching network units. The magnetron source was utilized to deposit metallic interlayers between the C100 substrate and the a-C:H coating. Ti (Aja International, Inc., purity 99.999\%) was utilized as metal targets. The gas flow rate is controlled in range $1-200$ sccm by means of mass flow controllers (MKS Instruments, Inc.) and the feed gas is admitted in the reactor through a ring encompassing the upper electrode.

The depositions were performed on substrates made of polished bi-lapped silicon (STMicroelectronics), for the chemical characterizations, and of C100 steel (Inac s.p.a.) with root mean square (RMS) surface roughness of 30 $\pm 10 \mathrm{~nm}$, for tribological investigations. Both kinds of substrate were previously cleaned in ethanol and acetone.

Before the a-C:H film deposition, two consecutive sputter cleaning steps with Ar (Airliquide, $8 \mathrm{sccm}$ ) at 1.33 Pa for 15 min each were performed. The first step, for substrate cleaning, was performed by powering the lower electrode with $100 \mathrm{~W}$. The second step, conducted by igniting a glow discharge at $100 \mathrm{~W}$ between the upper magnetron electrode and the grounded shutter plate, was carried out to clean the metal target. At the end of this cleaning, the shutter was open and the substrates were coated with a metallic interlayer (5, 35 or $70 \mathrm{~nm}$ thick) by powering the magnetron at $100 \mathrm{~W}, 1.33 \mathrm{~Pa}$ and $\mathrm{Ar}(8 \mathrm{sccm})$.

After the sputter deposition of the metal layer, the magnetron shutter was closed and the a-C:H deposition 


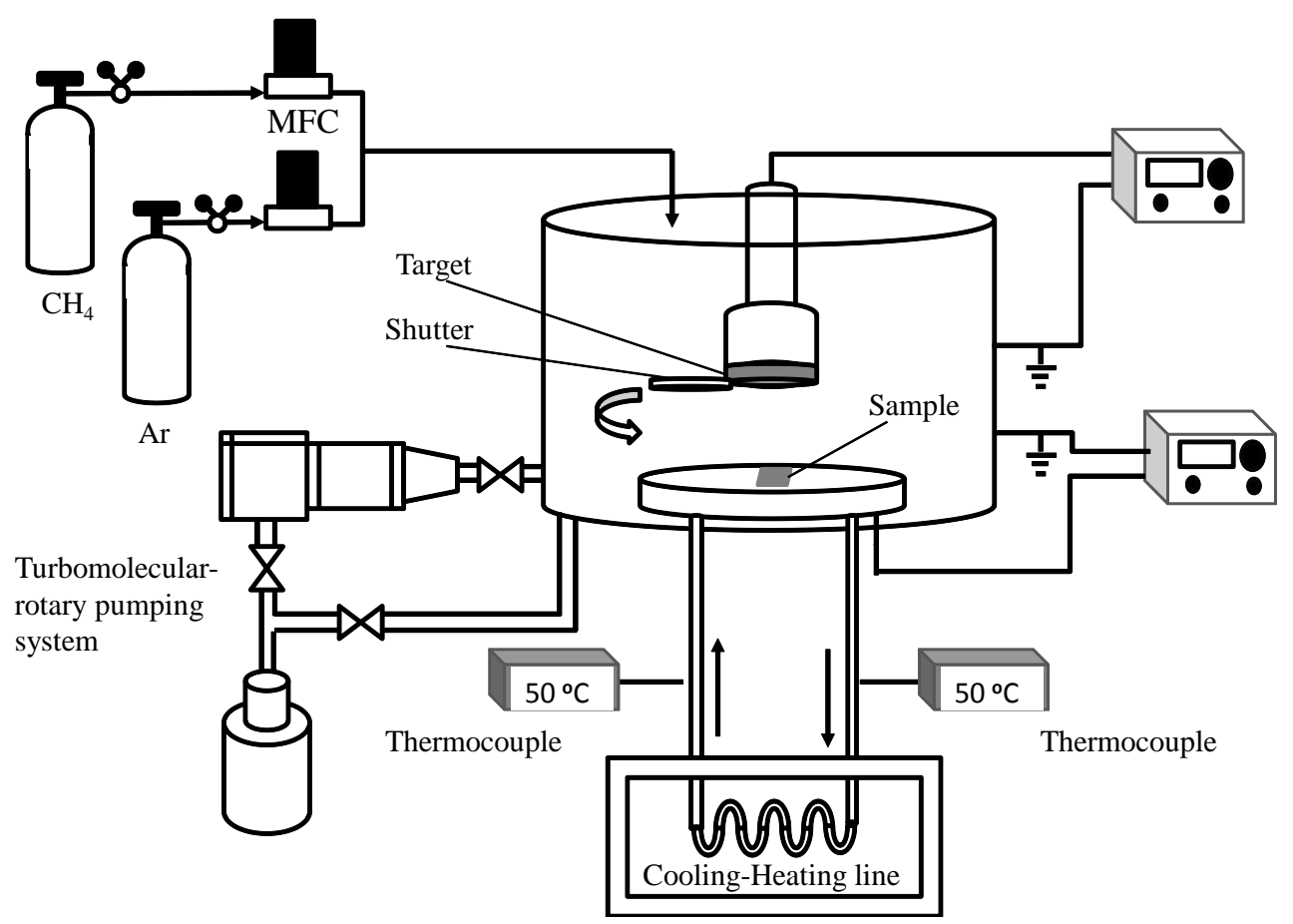

Figure 1. Scheme of the low pressure plasma reactor, with asymmetric electrode configuration, employed for cleaning and deposition processes.

started at $2.67 \mathrm{~Pa}$, with $\mathrm{Ar}(3 \mathrm{sccm})$ and $\mathrm{CH}_{4}$ (Airliquide, $23 \mathrm{sccm}$ ), by powering only the lower electrode at 40 $\mathrm{W}$, corresponding to a negative bias voltage of $300 \mathrm{~V}$.

The chemical characterization of deposited thin films was performed by means of RAMAN spectroscopy, X-ray photoelectron spectroscopy (XPS), elastic recoil detection analysis (ERDA) and Rutherford backscattering spectroscopy (RBS). RAMAN characterization was performed at room temperature with a HORIBA Jobin Yvon XploRA spectrometer, equipped with a true confocal microscopy (spatial resolution, $\sim 1 \mu \mathrm{m}$ ). For each sample, 20 spectra were acquired in $10 \mathrm{~s}$ using an excitation wavelength of $532.0 \mathrm{~nm}$.

XPS analyses were conducted using a Theta Probe spectrometer (Thermo Electron Corporation), equipped with monochromatic $\mathrm{Al} \mathrm{K} \alpha \mathrm{X}$-ray source $(1486.6 \mathrm{eV})$, operated at a spot size of $300 \mu \mathrm{m}$ (100 W power). Survey $(0-1200 \mathrm{eV})$ and high resolution (C1s and O1s regions) spectra were recorded at a pass energy of 150 and 100 $\mathrm{eV}$, respectively. All spectra were acquired at a take-off angle of $37^{\circ}$. A flood gun was used to balance surface charging. The C1s peak from the graphitic component, with the binding energy of $284.5 \mathrm{eV}$ [14], was used as the reference for calibration.

The surface atomic composition was also investigated with ERDA, for the quantification of $\mathrm{H}$ atom content, and $\mathrm{RBS}$ for $\mathrm{C}$ and $\mathrm{O}$ atoms determinations. The analyses were performed using a $3 \mathrm{MV}$ Tandetron accelerator (High Voltage Engineering). A beam of $\mathrm{He}^{2+}$ particles at $2.25 \mathrm{MeV}$ was focused on samples and two spectra were acquired at $160^{\circ}$ and $30^{\circ}$ of scattering angle, respectively. A $10 \mu \mathrm{m}$ thick Al foil on ERDA detector was used as an absorber foil to stop the scattered ions. The RBS and ERDA spectra were analyzed using the SIMNRA program. Figure 2 shows the detection geometry employed for ERDA and RBS analyses.

Nanoindentation, nanoscratch and nanowear measurements were performed using a triboindenter TI 750 UbiTM (Hysitron) equipped with a three-plate capacitive transducer, a Berkovich indenter and an in-situ scanning probe microscopy (SPM). Automated thermal-drift correction was made with an average drift rate, measured before starting each experiment. Before and after the series of experiments, the system operation was verified by performing similar force indents on the standard fused quartz sample, to check for system consistency.

XPS, RAMAN and tribomechanical measurements were repeated three times on three different samples prepared under the same experimental conditions.

The error of the ERDA and RBS analyses results was estimated on the basis of the experimental repeatability of the methods and it was assumed equal to $3 \%$. 


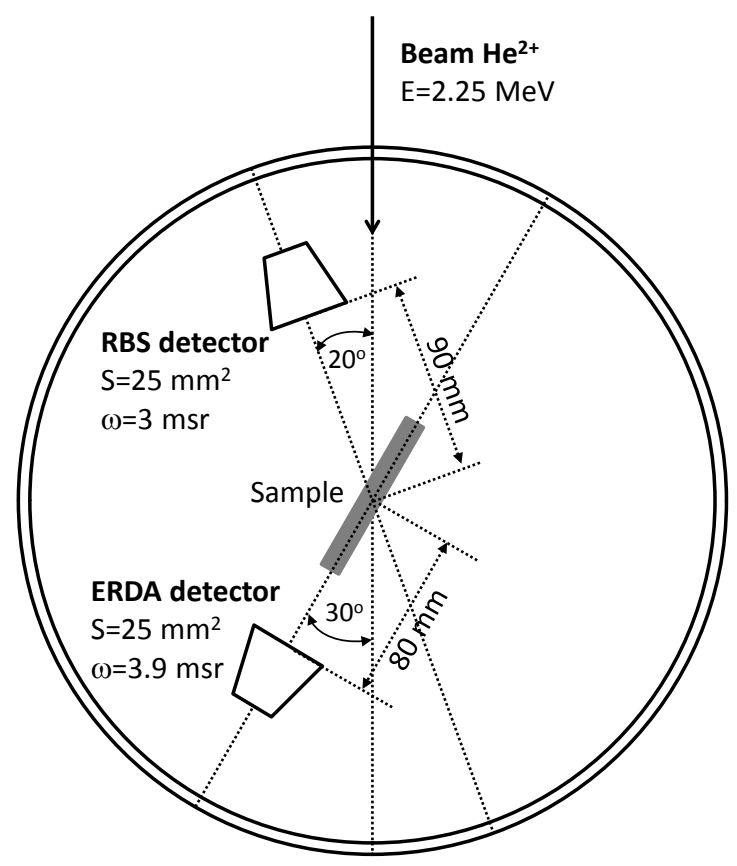

Figure 2. Detection geometry for ERDA and RBS analyses.

Finally, for the estimation of the thickness of each plasma deposited layer, a small area of the sample was covered by a silicon mask that created a step after deposition, reflecting the film thickness. Three steps on each specimen were used for thickness measurements, obtained by means of a KLA-Tencor AlphaStep ${ }^{\circledR}$ D-120 surface profilometry system.

\section{Results and Discussion}

\subsection{Determination of the $\mathrm{sp}^{3}$ and $\mathrm{sp}^{2}$ Content}

As previously underlined, the structure and properties of DLC films are affected by the ratio of $\mathrm{sp}^{2}$ to $\mathrm{sp}^{3}$ bonds of carbon atoms [3]. Due to the complexity of DLC structure, the determination of this ratio has been the subject of many studies [15]-[20]. However, it was not found a univocal relationship between the RAMAN data and the $\mathrm{sp}^{2}$ and $\mathrm{sp}^{3}$ content. For this reason, in this paper, RAMAN spectroscopy was used only for a qualitative investigation of the films.

The typical RAMAN spectrum of a a-C:H coating obtained in this work is reported in Figure 3.

The shape of the signal is compatible with the characteristic RAMAN spectrum reported in literature for DLC coatings [16].

The $\mathrm{sp}^{3}$-to-sp ${ }^{2}$ ratio can be calculated by XPS after best fitting of C1s signal performed with Avantage data spectrum processing software (Thermo Electron Corporation), utilizing the same factors of Leung et al. [17], Filik et al. [18] and Merel et al. [19], but with the introduction of a fourth peak relative to the carbon atoms having two bonds with oxygen (due to residual oxygen in the reaction chamber during PE-CVD processes).

The full width at half maximum (FWHM) value of each peak component was allowed to vary between 1.0 and $1.2 \mathrm{eV}$. The C1s peak from the $\mathrm{sp}^{2}$ graphitic component, with the binding energy of $284.5 \mathrm{eV}$, was used as the reference for calibration. The binding energies of the other three peaks were fixed at: a) $285.1 \pm 0.1 \mathrm{eV}$ for sp3 carbon atoms, b) $286.5 \pm 0.1 \mathrm{eV}$ for carbon atoms bounded to one oxygen atoms and c) $288.0 \pm 0.2 \mathrm{eV}$ for carbon atoms bounded to two oxygen atoms. The shape of all peaks was obtained setting the ratio Lorentzian/ Gaussian between 18 and 22.

The $\mathrm{Csp}^{3}$ value was about $55 \%$, which is the typical value reported for the a-C:H film deposited by means of PE-CVD [3]. Obviously, since XPS is a surface sensitive technique, this percentage should be strictly referred to the sample surface but, since it has been reported that for a tetrahedral amorphous carbon (ta-C) film the surface 


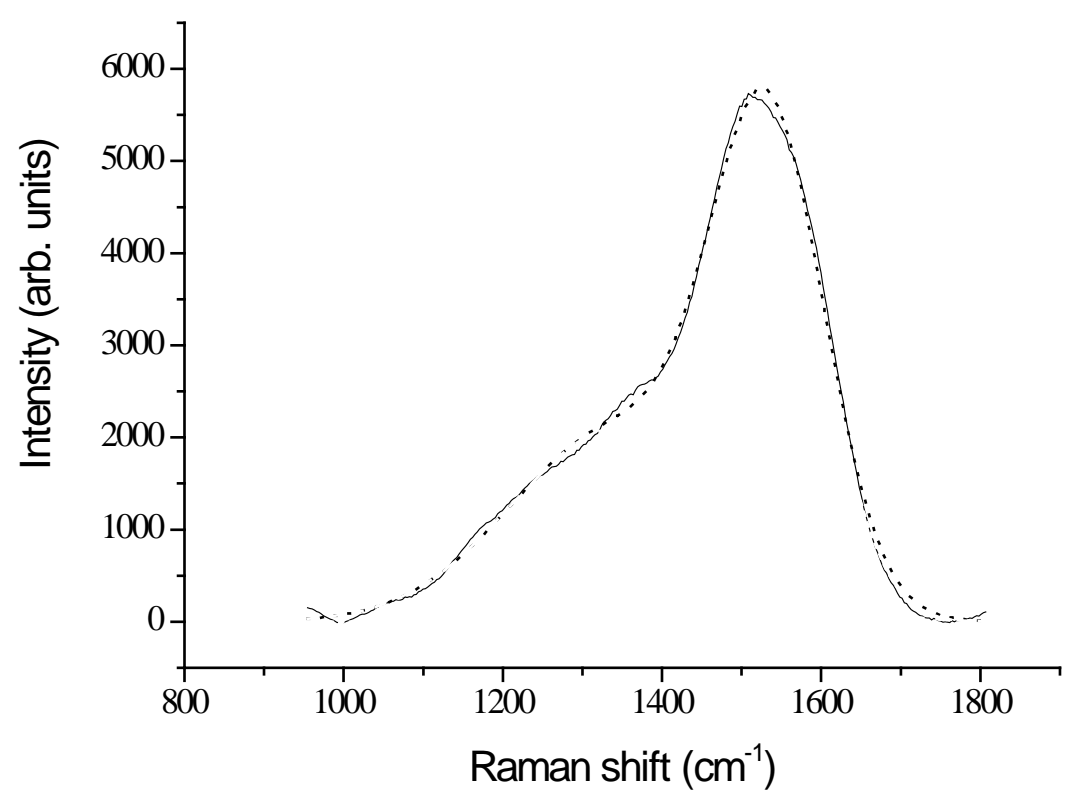

Figure 3. Example of RAMAN spectrum of a-C:H film, obtained at 2.67 $\mathrm{Pa}, \mathrm{Ar}(3$ sccm) and $\mathrm{CH}_{4}(23 \mathrm{sccm}), 40 \mathrm{~W}$ (300 V, bias voltage).

layers are often slightly richer in $\mathrm{Csp}^{2}$ than the bulk, we expect at least an underestimation of the XPS Csp ${ }^{3}$ content [18].

\subsection{RBS and ERDA Measurements}

The ERDA spectrum of a-C:H films, deposited on silicon substrates, shows the intense band of hydrogen between channels 75 and 175 (Figure 4(a)). Its atomic concentration resulted to be $33 \% \pm 3 \%$.

The RBS spectrum (Figure 4(b)) is characterized by the signals of carbon, oxygen and argon.

By the combination of the ERDA and RBS data, it results that the bulk chemical composition of the a-C:H films is: C, $63 \pm 3$ at\%; O, $4 \pm 1$ at\%; $\mathrm{H}, 33 \pm 3$ at\%. The concentration of Argon is lower that 0.5 at $\%$. This result is in good agreement with the XPS atomic oxygen concentration which is 7.3 at\%. In fact, if the atomic oxygen percent of ERDA and RBS is calculated neglecting the hydrogen, as it occurs with XPS, its concentration should be $6 \pm 1$ at\%.

\subsection{Interlayer Optimization}

The adhesion of a-C:H on flat $\mathrm{C} 100$ steel samples is very poor since spontaneous delamination occurs. In order to improve the adhesion, according to the strategies proposed by Huang et al. [20], Gerth and Wiklund [21], Pischow et al. [22], a metallic interlayer of Ti was deposited on the C100 steel surface for magnetron sputtering.

The adhesion of a-C:H thin film on the steel substrates coated with $\mathrm{Ti}$ interlayers was evaluated with loadcontrolled ramping force scratch tests. Each measurement consisted of a $10 \mu \mathrm{m}$ scratch length for 50 seconds.

For untreated sample a $1000 \mu \mathrm{N}$ load is enough to notch the surface while, for coated substrates, no evidence of scratching can be detected till at $2000 \mu \mathrm{N}$.

The adhesion strength was evaluated by ramping force nanoscratch experiments with peak load of $2000 \mu \mathrm{N}$ (10 $\mu \mathrm{m}$ run for $50 \mathrm{~s}$ ), performed to measure the critical load [23] (Table 1).

When a failure/delamination event occurs on the coated substrate, the data plot of the nanoscratch test shows a distinct change in the curve profile. The normal load corresponding to this event is defined as critical load ( $\left.\mathrm{P}_{\text {crit }}\right)$ [24]. The results of a typical nanoscratch experiments (Table 1), for a C100 sample coated with Ti interlayer (35 $\mathrm{nm}$ ) and $350 \mathrm{~nm}$ of a-C:H thin films, are represented in Figure 5.

The lateral and normal force versus time are reported; circles highlight the failure/delamination event in the lateral force plot and the correspondent critical load (at about 32 seconds) in the load normal force plot. 


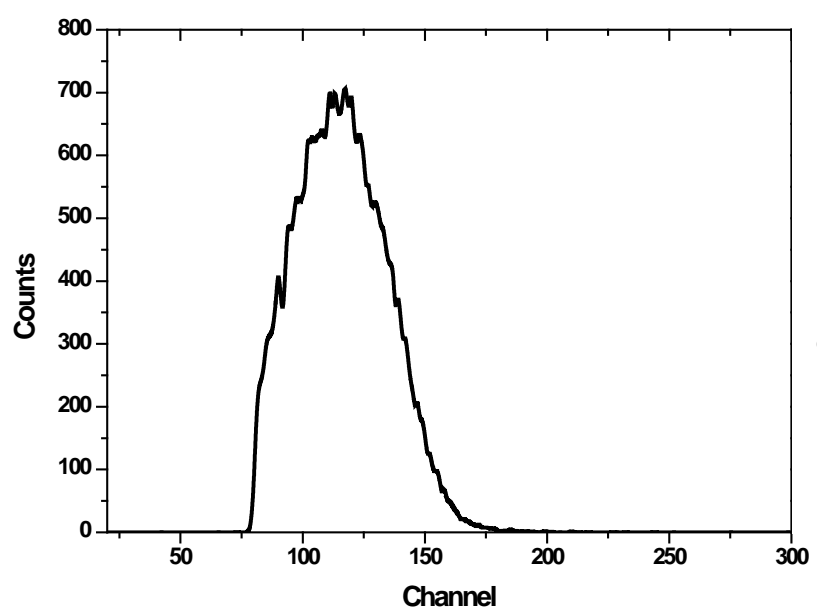

(a)

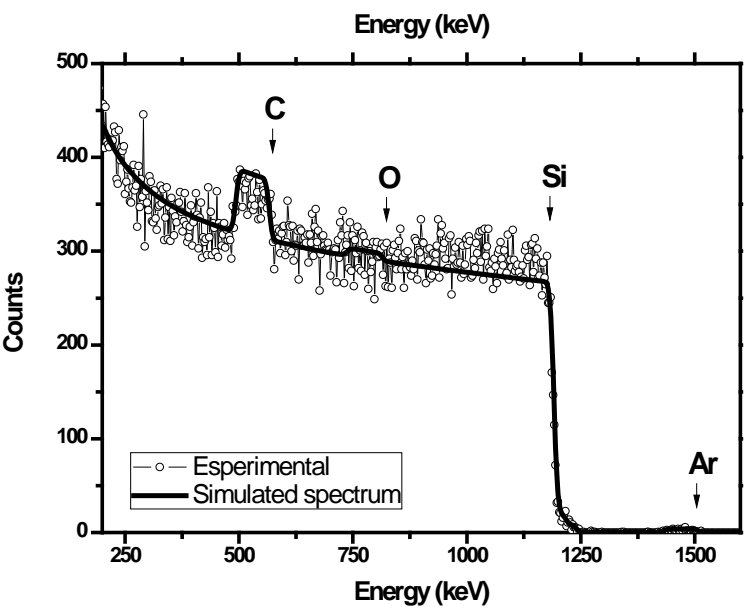

(b)

Figure 4. Example Typical ERDA (a) and RBS (b) spectra of a-C:H films.
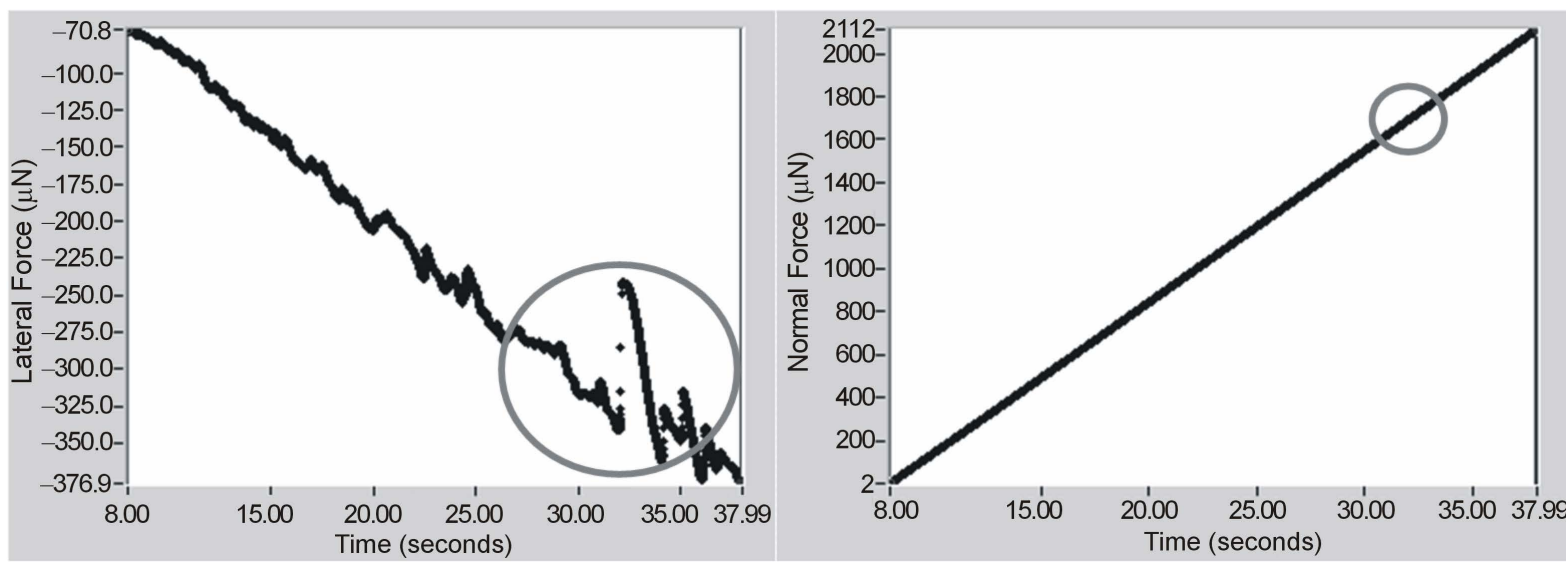

Figure 5. Ramping force nanoscratch with peak load $2000 \mu \mathrm{N}$ on C100 sample covered with $35 \mathrm{~nm}$ Ti interlayer and $350 \mathrm{~nm}$ of a-C:H film: failure/delamination event highlight in the lateral force versus time plot.

Table 1. Adhesion strength of a-C:H coating on C100 steel with Ti interlayer. Nanoscratch tests at peak load of $2000 \mu \mathrm{N}$.

\begin{tabular}{ccc}
\hline Ti interlayer thickness $(\mathrm{nm})$ & a-C:H film thickness $(\mathrm{nm})$ & Adhesion strength $(\mu \mathrm{N})$ \\
\hline 5 & 350 & $435 \pm 71$ \\
35 & 350 & $1690 \pm 50$ \\
70 & 350 & $1080 \pm 44$ \\
35 & 700 & $1132 \pm 54$ \\
70 & 700 & $1037 \pm 90$ \\
\hline
\end{tabular}

The adhesion of a-C:H film to the substrate depends on the thickness of the Ti interlayer, since the highest adhesion strength $(1690 \pm 50 \mu \mathrm{N})$ was detected for Ti interlayer $35 \mathrm{~nm}$ thick.

\subsection{Tribomechanical Properties}

Two kinds of nanoindentation measurements were performed for the nano-tribomechanical characterization of the a-C:H coating deposited on C100 steel with the Ti interlayers: a partial unloading and a load-controlled indentation test. The partial unloading experiments consist of 33 cycles ( $1 \mathrm{~s}$ loading, $1 \mathrm{~s}$ hold and $1 \mathrm{~s}$ unloading) 
with progressive increase of the load with a peak of $1000 \mu \mathrm{N}$. Since the purpose of these tests was to confirm that measurements are not affected by the substrate, the indentation depth was less than $10 \%$ of the film thickness [25].

Load-controlled indentation tests were performed with peak indentation load of $600 \mu \mathrm{N}$, in order to avoid the effect of substrate. Nine indents, composed by $5 \mathrm{~s}$ loading, $2 \mathrm{~s}$ hold and $5 \mathrm{~s}$ unloading, were performed on each sample. The results, in terms of Hardness (H) and reduced modulus (Er) are reported in Table 2.

It can be appreciated that the a-C:H deposits on C100 steel, optimized in the present study, are characterized by the typical hardness values published for this class of deposits ( 16 GPa) [3].

The wear resistance was evaluated by scanning wear tests, which consists of four passes of Berkovich probe with a scan size of $5 \mu \mathrm{m}$, tip velocity of $20 \mu \mathrm{m} / \mathrm{s}$ at normal load of 100, 150 and $200 \mu \mathrm{N}$. After each wear test, the region was imaged using a $10 \mu \mathrm{m}$ scan size (Figure 6) and the image was analyzed by means of Hysitron TriboView software, to calculate the wear volume according to the following formula [26]:

$$
\text { Wear volume }\left[\mu \mathrm{m}^{3}\right]=\text { wear scan } \operatorname{size}^{2}\left[\mu \mathrm{m}^{2}\right] \times \text { wear height }[\mu \mathrm{m}]
$$

where the wear height is obtained by the difference between the height outside and inside the wear region.

The wear test results indicate that any appreciable wear occurs on coated samples at normal loads of $100 \mu \mathrm{N}$ and $150 \mu \mathrm{N}$ if compared with untreated C100 steel (wear volume of $255 \times 10^{-2} \mu \mathrm{m}^{3}$ and $298 \times 10^{-2} \mu^{3}$, respectively); while a wear volume of $124 \times 10^{-2} \mu^{3}$ is registered at $200 \mu \mathrm{N}$ for sample characterized by the thicker layers (70 $\mathrm{nm}$ Ti and $700 \mathrm{~nm}$ a-C:H coating).

The tribomechanical tests allow to conclude that, under the experimental conditions utilized in the present study, the best coating on C100 steel is obtained by depositing $350 \mathrm{~nm}$ of a-C:H thin film over $35 \mathrm{~nm}$ of Ti interlayer.

Table 2. Results of the load-controlled nanoindentation tests on C100 steel coated with Ti/a-C:H film.
\begin{tabular}{ccccc}
\hline Sample N & Ti thickness (nm) & a-C:H film thickness (nm) & H (GPa) & Er (GPa) \\
\hline 0 & 0 & 0 & $9 \pm 1$ & $177 \pm 9$ \\
1 & 5 & 350 & $14 \pm 1$ & $133 \pm 12$ \\
2 & 35 & 350 & $16 \pm 2$ & $142 \pm 10$ \\
3 & 35 & 700 & $16 \pm 2$ & $148 \pm 18$ \\
4 & 70 & 350 & $16 \pm 1$ & $136 \pm 12$ \\
5 & 70 & 700 & $15 \pm 3$ & $128 \pm 20$ \\
\hline
\end{tabular}

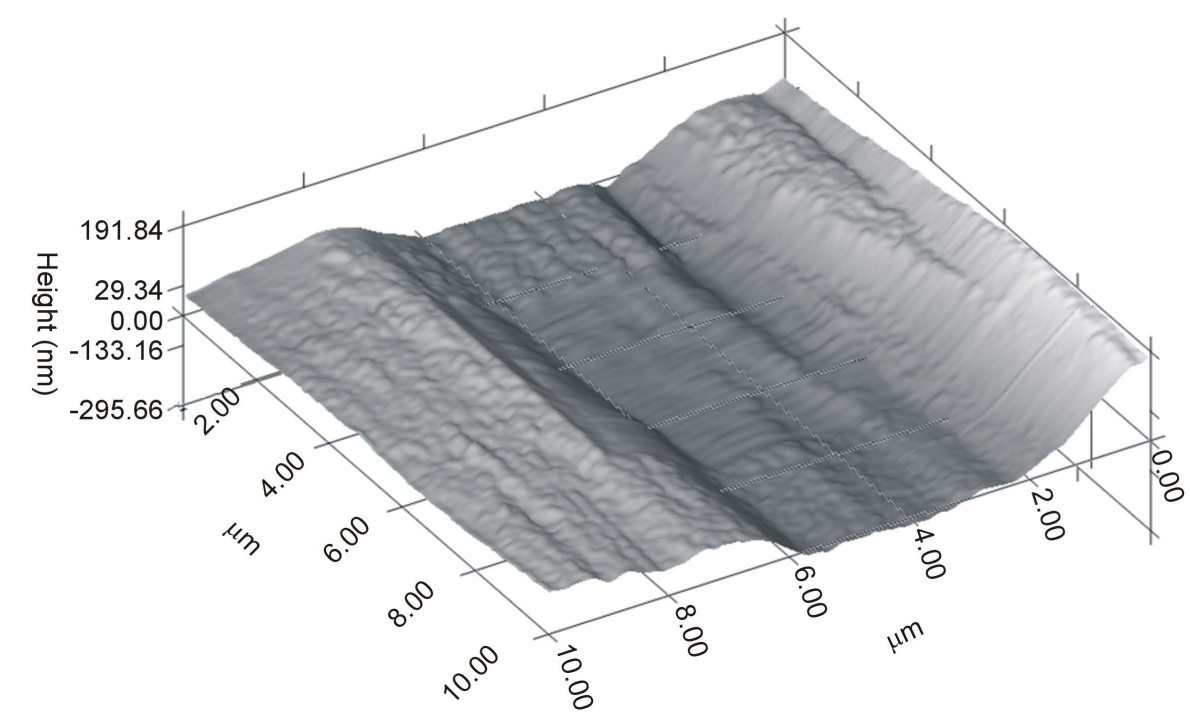

Figure 6. Representative $10 \mu \mathrm{m}$ 3-D in-situ scanning probe microscopy (SPM) images of the C100 surface after the wear tests at normal load of $200 \mu \mathrm{N}$ on sample covered with $70 \mathrm{~nm} \mathrm{Ti}$ interlayer thickness and $700 \mathrm{~nm}$ of a-C:H film. 


\section{Conclusions}

In this paper it has been shown that a hard and well adherent a-C:H thin film can be deposited by PE-CVD on C100 steel, if a thin Ti interlayer (35 nm thick) is deposited by magnetron sputtering.

The hydrogen content, the $\mathrm{C} \mathrm{sp}{ }^{3}$-to-sp ${ }^{2}$ ratio and the hardness values, obtained in the present work, are in line with those reported in the literature for typical a-C:H film, deposited by PE-CVD.

The ERDA and RBS data, in agreement with the surface composition determined by XPS, show that the chemical composition of the a-C:H films is: C, $63 \pm 3$ at\%; O, $4 \pm 1$ at\%; H, $33 \pm 3$ at\%. The amount of Ar inglobated in the coating during the plasma deposition is lower that 0.5 at $\%$.

The tribological properties of the a-C:H films on C100 steel are excellent, both in terms of adhesion (adhesion strength, $\sim 1700 \mu \mathrm{n}$ ) and hardness (16 GPa), suggesting that treated C100 steel should be a promising material for the production, for example, of diesel engine components, the injection pump plungers, in particular. For this application, in fact, it is necessary to have not only good surface hardness, but also excellent adhesion of the hard coating to the steel substrate. The excellent adhesion is needed in order to prevent dethatching from the sliding surface of oscillating elements, which may cause the formation of debris that scrape the steel causing loss of injector performance.

\section{Acknowledgements}

This research was financially supported by: Regione Puglia Progetto DM01 “Sensori e microlavorazioni laser per applicazioni in motoristiche e manufatturiere"; Progetto n. 51 "Laboratorio pubblico di ricerca industriale pugliese dei plasmi, LIPP” within the Framework Programme Agreement APQ “Ricerca Scientifica”, II atto integrativo-Reti di Laboratori Pubblici di Ricerca and by MIUR PON 2007-2013_01_02238 “Elettronica di controllo, sistema d'iniezione, strategie di combustione, sensoristica e tecnologie di processo innovativi per motori diesel a basse emissioni inquinanti”.

Dr. Pasqua Rossini is kindly acknowledged for her scientific contribution.

A special thanks also to Dr. Annarosa Mangone for RAMAN analyses.

\section{References}

[1] Jarry, O., Jaoul, C., Tristant, P., Merle-Méjean, T., Colas, M., Dublanche-Tixier, C., Ageorges, H., Lory, C. and Jacquet, J.-M. (2009) Tribological Behaviour of Diamond-Like Carbon Films Used in Automotive Application: A Comparison. Plasma Processes and Polymers, 6, S478-S482. http://dx.doi.org/10.1002/ppap.200931007

[2] Lawes, S.D.A., Fitzpatrick, M.E. and Hainsworth, S.V. (2007) Evaluation of the Tribological Properties of DLC for Engine Applications. Journal of Physics D: Applied Physic, 40, 5427-5437. http://dx.doi.org/10.1088/0022-3727/40/18/S03

[3] Robertson, J. (2002) Diamond-Like Amorphous Carbon. Materials Science and Engineering: R: Reports, 37, $129-281$. http://dx.doi.org/10.1016/S0927-796X(02)00005-0

[4] Nir, D. (1987) Intrinsic Stress in Diamond-Like Carbon Films and Its Dependence on Deposition Parameters. Thin Solid Films, 146, 27-43. http://dx.doi.org/10.1016/0040-6090(87)90337-3

[5] Voevodin, A.A., Walck, S.D. and Zabinski, J.S. (1997) Architecture of Multilayer Nanocomposite Coatings with Super-Hard Diamond-Like Carbon Layers for Wear Protection at High Contact Loads. Wear, 203-204, 516-527. http://dx.doi.org/10.1016/S0043-1648(96)07425-X

[6] Miyoshi, K., Pohlchuck, B., Street, K.W., Zabinski, J.S., Sanders, J.H., Voevodin, A.A. and Wu, R.L.C. (1999) Sliding Wear and Fretting Wear of Diamond-Like Carbon-Based, Functionally Graded Nanocomposite Coatings. Wear, 225229, 65-73. http://dx.doi.org/10.1016/S0043-1648(98)00349-4

[7] Su, Y.L. and Kao, W.H. (2000) Optimum Me-DLC Coatings and Hard Coatings for Tribological Performance. Journal of Materials Engineering and Performance, 9, 38-50. http://dx.doi.org/10.1361/105994900770346268

[8] Czyzniewski, A. (2012) Optimising Deposition Parameters of W-DLC Coatings for Tool Materials of High Speed Steel and Cemented Carbide. Vacuum, 86, 2140-2147. http://dx.doi.org/10.1016/j.vacuum.2012.06.011

[9] Yue, Z.W., Zhang, H., Dou, B.Y. and Han, P.F. (2010) Experimental Study on Microcosmic and Microscopic Properties of C100 High-Strength Concrete. Advanced Materials Research, 2529, 168-170. http://dx.doi.org/10.4028/www.scientific.net/AMR.168-170.2529

[10] Batory, D., Szymański, W. and Cłapa, M. (2013) Mechanical and Tribological Properties of Gradient a-C:H/Ti Coatings. Materials Science-Poland, 31, 415-423. http://dx.doi.org/10.2478/s13536-013-0121-9 
[11] Wei, C. and Chen, C.-H. (2008) The Effect of Thermal and Plastic Mismatch on Stress Distribution in Diamond like Carbon Film under Different Interlayer/Substrate System. Diamond and Related Materials, 17, 1534-1540. http://dx.doi.org/10.1016/j.diamond.2008.03.004

[12] Deng, J.G. and Braun, M. (1995) DLC Multilayer Coatings for Wear Protection. Diamond and Related Materials, 4, 936-943. http://dx.doi.org/10.1016/0925-9635(94)00256-8

[13] Malcolm, G., Naylor, F., Kodali, P. and Wang, J.C. (2011) Modern Tribology Handbook (Vol. 3, Editor-in-Chief Bharat Bhushan). CRC Press LLC, Boca Raton.

[14] Moulder, J.F., Stickle, W.F., Sobol, P.E., Bomben, K.D. and Chastain, J. (1992) In: Chastain, J., Ed., Handbook of $X$-Ray Photoelectron Spectroscopy: A Reference Book of Standard Spectra for Identification and Interpretation of XPS Data, Perkin-Elmer Corporation, Waltham.

[15] Gassner, G., Mayrhofer, P.H., Patscheider, J. and Mitterer, C. (2007) Thermal Stability of Nanocomposite CrC/a-C:H Thin Films. Thin Solid Films, 515, 5411-5417. http://dx.doi.org/10.1016/j.tsf.2006.12.149

[16] Irmer, G. and Dorner-Reisel, A. (2005) Micro-Raman Studies on DLC Coatings. Advanced Engineering Materials, 7, 694-705. http://dx.doi.org/10.1002/adem.200500006

[17] Leung, T.Y., Man, W.F., Lim, P.K., Chan, W.C., Gaspari, F. and Zukotynski, S. (1999) Determination of the $\mathrm{sp}^{3} / \mathrm{sp}^{2}$ Ratio of a-C:H by XPS and XAES. Journal of Non-Crystalline Solids, 254, 156-160. http://dx.doi.org/10.1016/S0022-3093(99)00388-9

[18] Filik, J., May, P.W., Pearce, S.R.J., Wild, R.K. and Hallam, K.R. (2003) XPS and Laser RAMAN Analysis of Hydrogenated Amorphous Carbon Films. Diamond and related Materials, 12, 974-978. http://dx.doi.org/10.1016/S0925-9635(02)00374-6

[19] Merel, P., Tabbal, M., Chaker, M., Moisa, S. and Margot J. (1998) Direct Evaluation of the $\mathrm{sp}^{3}$ Content in Diamond-like-Carbon Films by XPS. Applied Surface Science, 136, 105-110. http://dx.doi.org/10.1016/S0169-4332(98)00319-5

[20] Huang, J.H., Ouyang, F.Y. and Yu, G.P. (2007) Effect of Film Thickness and Ti Interlayer on the Structure and Properties of Nanocrystalline TiN Thin Films on AISI D2 Steel. Surface and Coatings Technology, 201, 7043-7053. http://dx.doi.org/10.1016/j.surfcoat.2007.01.012

[21] Gerth, J. and Wiklund, J.U. (2008) The Influence of Metallic Interlayers on the Adhesion of PVD TiN Coatings on High Speed Steel. Wear, 264, 885-892. http://dx.doi.org/10.1016/j.wear.2006.11.053

[22] Pischow, K.A., Eriksson, L., Harju, E., Korhonen, A.S. and Ristolainen, E.O. (1993) The Influence of Titanium Interlayers on the Adhesion of PVD-Tin Coatings on Oxidized Stainless-Steel Substrates. Surface and Coatings Technology, 58, 163-172. http://dx.doi.org/10.1016/0257-8972(93)90003-7

[23] Burakowski, T. and Wierzhon, T. (1999) Surface Engineering of Metals-Principles, Equipment and Technologies. CRC Press LLC, Boca Raton.

[24] Schirer, J., Nowak, J., Kusano, E. and Sakamoto, M. (2011) Full Nanomechanical Characterization of Ultra-Thin Films. Hysitron Application Note.

[25] Fischer-Cripps, A.C. (2011) Nanoindentation. 3rd Edition, Springer, Berlin. http://dx.doi.org/10.1007/978-1-4419-9872-9

[26] TI 750 Ubi User Manual (2011) Revision 9.2.0311, Copyright $\subset$ Hysitron Incorporated. 